\title{
Review Article \\ Effect of C-Peptide on Diabetic Neuropathy in Patients with Type 1 Diabetes
}

\author{
Karin Ekberg and Bo-Lennart Johansson \\ Department of Molecular Medicine and Surgery, Karolinska Institute, 17176 Stockholm, Sweden \\ Correspondence should be addressed to Karin Ekberg, karin.ekberg@creativepeptides.se
}

Received 9 October 2007; Accepted 27 December 2007

Recommended by Thomas Forst

Recent results indicate that proinsulin C-peptide, contrary to previous views, exerts important physiological effects and shows the characteristics of a bioactive peptide. Studies in type 1 diabetes, involving animal models as well as patients, demonstrate that Cpeptide in replacement doses has the ability to improve peripheral nerve function and prevent or reverse the development of nerve structural abnormalities. Peripheral nerve function, as evaluated by determination of sensory nerve conduction velocity and quantitative sensory testing, is improved by C-peptide replacement in diabetes type 1 patients with early stage neuropathy. Similarly, autonomic nerve dysfunction is ameliorated following administration of C-peptide for up to 3 months. As evaluated in animal models of type 1 diabetes, the improved nerve function is accompanied by reversal or prevention of nerve structural changes, and the mechanisms of action are related to the ability of C-peptide to correct diabetes-induced reductions in endoneurial blood flow and in $\mathrm{Na}^{+}, \mathrm{K}^{+}$-ATPase activity and modulation of neurotrophic factors. Combining the results demonstrates that C-peptide may be a possible new treatment of neuropathy in type 1 diabetes.

Copyright (c) 2008 K. Ekberg and B.-L. Johansson. This is an open access article distributed under the Creative Commons Attribution License, which permits unrestricted use, distribution, and reproduction in any medium, provided the original work is properly cited.

\section{INTRODUCTION}

Neuropathy is one of the most common long-term complications accompanying diabetes mellitus. It affects patients with both type 1 and type 2 diabetes, but it progresses more rapidly and its manifestations are more severe in type 1 diabetes [1,2]. Diabetic neuropathy is defined by the presence of detectable sensory, motor, and autonomic deficits on clinical examination, with or without the presence of symptoms $[3,4]$. As many as $50 \%$ of the patients may be asymptomatic, diagnosis may only be made on examination or, in some cases, when the patient presents with a painless foot ulcer [5]. Other patients may not volunteer symptoms but on inquiry admit that their feet feel numb or dead. A thorough neurological examination of the lower limb usually reveals sensory loss of vibration, pressure, pain, and temperature perception mediated by small and large fibers, and absent ankle reflexes. In addition to manifestations of autonomic neuropathy, for example, impaired cardiovascular and gastrointestinal functions, signs of peripheral sympathetic autonomic dysfunction are also frequently seen in patients with diabetes and may include a warm or cold foot, sometimes with distended dorsal foot veins, dry skin, and the presence of calluses under pressure-bearing areas. Diabetic neuropathies may present as rapidly reversible hyperglycemic neuropathy and focal or multifocal neuropathies, but the most relevant clinical form is the persistent distal symmetric polyneuropathy (DSPN) [4].

The DSPN is characterized as a gradual progression in structural changes consisting of distal axonal degeneration of "dying-back" type $[6,7]$ most prominent in the lower limbs, but involves also small fiber sensory dysfunction early in the course of the condition [7]. The prevalence of DSPN is approximately $30 \%$ for diabetes patients in general [8], but the number varies greatly in the literature related to the definition chosen for presence of diabetic neuropathy and the methodology chosen to assess its presence. Clinical examinations and patients' symptom assessment are considered important tools in the evaluation of neuropathy status, but both techniques rely greatly on subjective components and have thus poor reproducibility and specificity. Assessments using more objective markers of polyneuropathy, 


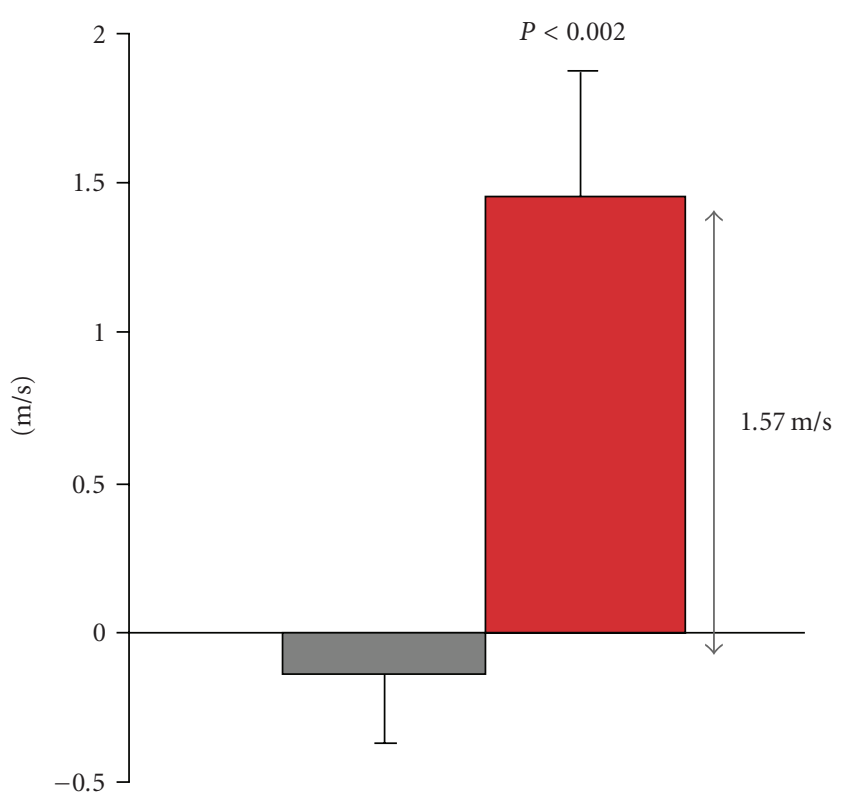

FIGURE 1: Change in peak sensory nerve conduction velocity in the sural nerves following 3-6 months of C-peptide replacement treatment (red bar) or placebo (gray bar) to patients with type 1 diabetes. The figure presents pooled data from $[19,20]$.

such as especially nerve conduction velocity (NCV) but also vibration perception threshold (VPT), may serve not only as reliable methods for detection of neuropathy, but the result may also be used for the prediction of mortality in diabetic patients $[9,10]$. The pathogenesis of diabetic neuropathy involves metabolic effects mediated directly and indirectly by hyperglycemia, resulting in oxidative stress, accelerated polyol pathway metabolism and generation of advanced glycation endproducts [11-13]. Furthermore, diabetic neuropathy is accompanied by reduced nerve $\mathrm{Na}^{+}, \mathrm{K}^{+}$-ATPase activity, and microvascular abnormalities (e.g., reduced endoneurial perfusion) [14]. Type 1 diabetes is associated with specific structural nerve abnormalities that are not frequent in type 2 diabetes. These abnormalities include axonal atrophy and characteristic nodal and paranodal changes that contribute to the progressive deterioration of nerve conduction velocity [15-17]. In contrast, in type 2 diabetes the axonal degeneration is milder and no or only minimal nodal and paranodal abnormalities occur [17, 18]. However, after several years type 2 diabetes often become insulin and Cpeptide deficient, and at this stage it is most likely that the type 2 DSPN will start presenting with characteristics similar to that of type 1 neuropathy.

In the case of type 1 diabetes, available data suggest that C-peptide deficiency is an important contributing factor to the characteristic structural abnormalities [21]. In conformity with this hypothesis several studies have demonstrated that it is possible to retard the progression of diabetic complications by intensified insulin treatment and improved metabolic control, but development of neuropathy cannot be prevented [22-24]. Thus, other factors, such as C-peptide deficiency, are likely to be of importance for the progres- sion of diabetic neuropathy in type 1 diabetes. Evidence documenting significant physiological effects of C-peptide has been presented during the latest decades. It shows that Cpeptide, in contrast to previous belief, possesses the characteristics of a bioactive peptide. C-peptide binds specifically to various cell membranes, including endothelial, renal and nerve cells [25], with subsequent activation of an intracellular signaling cascade resulting in stimulation of endothelial nitric oxide synthase (eNOS) and $\mathrm{Na}^{+}, \mathrm{K}^{+}$-ATPase [26]. Moreover, recent data indicate that C-peptide stimulates several transcriptional factors, as well as several neurotrophic factors [27]. Thus, it has been demonstrated that exogenous administration of C-peptide in replacement dose to patients lacking endogenous $\mathrm{C}$-peptide results in restoration of reduced blood flow in several tissues [28-31] and improvement of renal [32] and nerve function, the latter reviewed below. It is also a long-standing clinical observation that compared with type 1 diabetes patients in whom beta-cell secretion ceases totally, those patients who retain a low-endogenous C-peptide and insulin secretion are less prone to develop microvascular long-term complications involving the kidneys, the eyes, or the nervous system [33-35].

\section{CLINICAL STUDIES ON C-PEPTIDE AND NERVE FUNCTION}

To date, only a few studies on the clinical effects of Cpeptide on nerve function have been performed, but several preclinical studies indicate significant effects on diabetesinduced nerve dysfunction and structural abnormalities [3638]. The available clinical results indicate beneficial effects of C-peptide on both peripheral and autonomic nerve function in type 1 diabetes patients. Thus, in a double-blind, placebocontrolled study including 46 type 1 diabetes patients, with an average age of 29 years and approximately 10 years of diabetes duration, and with reduced sensory nerve and motor nerve conduction velocities (NCV) but no other signs of neuropathy, C-peptide replacement $(1.8 \mathrm{mg} /$ day $)$ or placebo was given for 3 months together with the patients' regular insulin therapy [19]. Sensory nerve conduction velocity assessed in the sural nerve bilaterally, but not motor NCV (peroneal nerve), increased gradually during the study. The increase after 3 months amounted to $2.7 \mathrm{~m} / \mathrm{s}$, corresponding to an $80 \%$ correction of the initial conduction velocity deficit in these patients. This change was accompanied by an improvement in vibration perception assessed on the dorsum of the feet, although these patients had essentially normal perception thresholds already at baseline. This improvement is consistent with an improved sural nerve function since vibration perception in this anatomic region is primarily mediated via the large fibers of the sural nerve.

The improvement in nerve function demonstrated in this early patient population is now confirmed and extended in a recently completed clinical trial including patients with diabetic neuropathy [20]. The study was a double-blind, placebo-controlled, randomized multicenter study, including 161 type 1 diabetes patients, with an average age of 44 years and 29 years of diabetes duration and defined DSPN (according to the San Antonio criteria [3]). At baseline their 
sensory nerve conduction velocity assessed in the sural nerve (SCV) was on average 2.6 SD below normal, and following 6 months of C-peptide replacement treatment there was a statistically significant improvement in SCV for the patients receiving C-peptide, amounting to $0.48 \pm 0.19 \mathrm{~m} / \mathrm{s}$ assessed as peak velocities and $0.93 \pm 0.29 \mathrm{~m} / \mathrm{s}$ for the initial response (the velocity change from baseline for the fastest axon in the nerve). However, these changes were not statistically significantly different from the change in the placebo group. The number of responders, defined as patients with an improvement in peak SCV $>1 \mathrm{~m} / \mathrm{s}$, was statistically significantly greater in the group receiving $\mathrm{C}$-peptide as compared to those receiving placebo (37\% versus $19 \%$, resp., $p<$ .032). It is noteworthy though that among the included patients some had substantial nerve conduction deficits at baseline and with the study duration of no more than 6 months it is conceivable that the patients who were relative less affected at baseline may have a greater potential for improvement. Thus, a subgroup analysis was performed in the subset of patients with the least affected SCV at baseline (half of the patient population). In this group, $\mathrm{C}$-peptide administration for 6 months resulted in an improvement that was $1.03 \mathrm{~m} / \mathrm{s}$ greater as compared to the change in the corresponding placebo treated patients $(P<.014)$. Analyzing the number of responders in this half of the patient population revealed that among patients receiving C-peptide, 39\% demonstrated an improvement in SCV $>1 \mathrm{~m} / \mathrm{s}$ whereas only $5 \%$ among the placebo treated patients showed a similar change $P<$ .004. Accompanying these changes in sural nerve conduction velocity there where, however, no statistically significant change in motor nerve conduction velocity, but there was an improvement within the C-peptide treated patients for vibration perception. There was also a trend towards an improvement in neurological examination scores following Cpeptide. Combining these data provides evidence of a therapeutic improvement of diabetes-induced peripheral nerve dysfunction following C-peptide administration in patients with type 1 diabetes; 3-6 months of C-peptide replacement to patients with early stage neuropathy resulted in approximately $1.5 \mathrm{~m} / \mathrm{s}$ in sensory nerve conduction velocity (see Figure 1) accompanied by other signs of nerve function improvements.

There is also evidence of beneficial effects of C-peptide administration to type 1 patients with signs of autonomic neuropathy. Deficient autonomic nerve function may be evaluated in patients as reduced heart rate variability (HRV) during deep breathing, a measurement that, with a high degree of reproducibility, primarily reflects vagal function. $\mathrm{Pa}$ tients were studied twice under normoglycemic conditions and during 3-hours intravenous infusion of either human Cpeptide or saline in a double-blind study. At baseline HRV was reduced $13 \pm 1 \%$ (normal reference value $24 \%$ ) and during the C-peptide infusion which restored plasma concentrations to physiological levels, the HRV improved to $20 \pm 2 \%$, while no change was seen after saline infusion $(p<.001)$ [39]. The heart rate brake index after a tilting maneuver was also improved after C-peptide for 3 hours in the patients showing reduced index before the study. In agreement with these results, a 20\% improvement in HRV was seen after 3 months of C-peptide replacement in type 1 diabetes patients whereas no change or a slight deterioration was observed in the same patients during a placebo treatment period [32].

\section{TREATMENT OF DIABETIC NEUROPATHY}

There is no effective pharmaceutical therapy available for diabetic neuropathy today. The onset and the progression of the diabetes-induced abnormalities may be delayed by maintenance of good glycemic control [22-24]. In the DCCT, the incidences of diabetes neuropathy were substantially lower in patients on intensive insulin treatment as compared to conventional insulin therapy [23]. For the patients in the DCCT secondary prevention group, with an average age of 28 years and a diabetes duration of 9 years, the $2 \%$ improvement in $\mathrm{HbA}_{1 \mathrm{c}}$ seen following 5 years of intensified insulin treatment was accompanied by an improved SCV of $1.5 \mathrm{~m} / \mathrm{s}$ whereas patients with unchanged metabolic control in the conventional treatment group experienced a $2.2 \mathrm{~m} / \mathrm{s}$ reduction in SCV. Interestingly, the patients in this group are directly comparable to the patients in the first C-peptide intervention study (average age 29 years and diabetes duration of 10 years) where 3 months of C-peptide replacement resulted in $2.7 \mathrm{~m} / \mathrm{s}$ improvement in SCV, and it is of note that these patients were already on an intensified insulin treatment regimen [19]. The magnitude of the response following C-peptide replacement treatment occurred completely independent of improved glycemic control, and in fact in top of an already good glycemic control. This suggests that the C-peptide is in fact acting on DSPN disease-modifying mechanisms. Impaired nerve blood flow secondary to perturbed nitric oxide metabolism $[36,38]$ and reduced levels of nerve $\mathrm{Na}^{+}, \mathrm{K}^{+}$-ATPase activity $[40,41]$ are both factors that have been implicated in the pathogenesis of the DSPN [7]. The ability of C-peptide to improve endoneurial blood flow and $\mathrm{Na}^{+}, \mathrm{K}^{+}$-ATPase activity as well as its stimulation of neurotrophic factors as demonstrated in several animal models of type 1 diabetes $[27,37,40]$ is thus likely to contribute to the positive effects of the peptide.

In addition to improved insulin therapy, most therapeutic interventions previously evaluated for DSPN have been directed toward correction of the adverse effects of hyperglycemia. For example, one approach involves the reduction of the intracellular sorbitol accumulation by aldose reductase inhibitors (ARI). Although shown to have beneficial effects on neuropathy $[42,43]$, several clinical trials involving ARIs have been discontinued because of unacceptable adverse effects, for example, skin rash, renal toxicity, and serious hepatic effects [44]. A new and apparently well-tolerated ARI, ranirestat, is currently in development, and phase II data indicate that its administration for 60 weeks to mostly type 2 diabetes patients has beneficial effects on nerve function $[45,46]$. Another compound also aiming to minimize the effects of hyperglycemia is the specific protein kinase $\mathrm{C}$ beta inhibitor, ruboxistaurin, but recent clinical development has not documented impressive clinical effect [47].

It has become increasingly apparent that DSPN presents a clear unmet medical need, and the health authorities and representatives for patient associations have expressed their 
concern [5]. Previously, the regulatory agencies have required efficacy on symptom relief and reduced wound and amputation frequency in order to accept a new drug application. However, it is now becoming increasingly recognized that treatment should be started well, before the deterioration of nerve function has reached the stage of severe symptoms and wounds. Moreover, the treatment should not only be directed at a symptom relief but to modify the underlying disease mechanisms. In the case of peripheral neuropathy accompanying type 1 diabetes, the beneficial effects on nerve function following C-peptide replacement therapy may indicate a new potential treatment paradigm, even though extended clinical trials will be needed to finally elucidate its usefulness.

\section{REFERENCES}

[1] P. Dyck, J. Davies, D. Wilson, F. Service, L. J. Melton, and P. O'Brien, "Risk factors for severity of diabetic polyneuropathy: intensive longitudinal assessment of the Rochester Diabetic Neuropathy Study cohort," Diabetes Care, vol. 22, no. 9, pp. 1479-1486, 1999.

[2] K. Sugimoto, Y. Murakawa, and A. A. F. Sima, "Diabetic neuropathy - a continuing enigma," Diabetes/Metabolism Research and Reviews, vol. 16, no. 6, pp. 408-433, 2000.

[3] A. K. Asbury, D. Porte Jr., S. M. Genuth, et al., "Report and recommendations of the San Antonio conference on diabetic neuropathy," Annals of Neurology, vol. 24, no. 1, pp. 99-104, 1988.

[4] D. Ziegler, "Treatment of diabetic polyneuropathy," Annals of the New York Academy of Sciences, vol. 1084, pp. 250-266, 2006.

[5] A. Boulton, A. Vinik, J. Arezzo, et al., "Diabetic neuropathies," Diabetes Care, vol. 24, no. 4, pp. 956-960, 2005.

[6] G. Said, G. Slama, and J. Selva, "Progressive centripetal degeneration of axons in small fibre diabetic polyneuropathy," Brain, vol. 106, no. 4, pp. 791-807, 1983.

[7] P. Thomas, "Diabetic neuropathy: mechanisms and future treatment options," Journal of Neurology Neurosurgery and Psychiatry, vol. 67, no. 3, pp. 277-279, 1999.

[8] J. Shaw, P. Zimmet, F. Gries, and D. Ziegler, "Epidemiology of diabetic neuropathy," in Textbook of Diabetic Neuropathy, F. Gries, N. E. Cameron, P. Low, and D. Ziegler, Eds., pp. 64-82, Thieme, Stuttgart, NY, USA, 2003.

[9] D. Coppini, P. Bowtell, C. Weng, P. Young, and P. Sönksen, "Showing neuropathy is related to increased mortality in diabetic patients - a survival analysis using an accelerated failure time model," Journal of Clinical Epidemiology, vol. 53, no. 5, pp. 519-523, 2000.

[10] C. M. Forsblom, T. Sane, P.-H. Groop, et al., "Risk factors for mortality in Type II (non-insulin-dependent) diabetes: evidence of a role for neuropathy and a protective effect of HLADR4," Diabetologia, vol. 41, no. 11, pp. 1253-1262, 1998.

[11] M. Brownlee, "The pathobiology of diabetic complications," Diabetes, vol. 54, no. 6, pp. 1615-1625, 2005.

[12] D. A. Greene, A. A. F. Sima, M. Stevens, E. L. Feldman, and S. A. Lattimer, "Complications: neuropathy, pathogenic considerations," Diabetes Care, vol. 15, no. 12, pp. 1902-1925, 1992.

[13] P. Low, K. Nickander, and L. Scionti, "Role of hypoxia, oxidative stress, and excitatory neurotoxins in diabetic neuropathy," in Diabetic Neuropathy, P. Dyck and P. Thomas, Eds., pp. 317 329, W.B. Saunders, Philadelphia, Pa, USA, 1999.
[14] N. E. Cameron, S. E. M. Eaton, M. A. Cotter, and S. Tesfaye, "Vascular factors and metabolic interactions in the pathogenesis of diabetic neuropathy," Diabetologia, vol. 44, no. 11, pp. 1973-1988, 2001.

[15] T. Brismar, A. A. F. Sima, and D. A. Greene, "Reversible and irreversible nodal dysfunction in diabetic neuropathy," Annals of Neurology, vol. 21, no. 5, pp. 504-507, 1987.

[16] P. Varghese Cherian, M. Kamijo, K. J. Angelides, and A. A. F. Sima, "Nodal $\mathrm{Na}^{+}$-channel displacement is associated with nerve-conduction slowing in the chronic diabetic $\mathrm{BB} / \mathrm{W}$ rat: prevention by aldose reductase inhibition," Journal of Diabetes and Its Complications, vol. 10, no. 4, pp. 192-200, 1996.

[17] A. A. F. Sima, V. Nathaniel, V. Bril, T. McEwen, and D. A. Greene, "Histopathological heterogeneity of neuropathy in insulin-dependent and non-insulin-dependent diabetes, and demonstration of axo-glial dysjunction in human diabetic neuropathy," Journal of Clinical Investigation, vol. 81, no. 2, pp. 349-364, 1988.

[18] Y. Murakawa, W. Zhang, C. R. Pierson, et al., "Impaired glucose tolerance and insulinopenia in the GK-rat causes peripheral neuropathy," Diabetes/Metabolism Research and Reviews, vol. 18, no. 6, pp. 473-483, 2002.

[19] K. Ekberg, T. Brismar, B.-L. Johansson, B. Jonsson, P. Lindström, and J. Wahren, "Amelioration of sensory nerve dysfunction by C-peptide in patients with Type 1 diabetes," Diabetes, vol. 52, no. 2, pp. 536-541, 2003.

[20] K. Ekberg, T. Brismar, B.-L. Johansson, et al., "C-peptide replacement therapy and sensory nerve function in Type 1 diabetic neuropathy," Diabetes Care, vol. 30, no. 1, pp. 71-76, 2007.

[21] A. A. F. Sima, "New insights into the metabolic and molecular basis for diabetic neuropathy," Cellular and Molecular Life Sciences, vol. 60, no. 11, pp. 2445-2464, 2003.

[22] DCCT Research Group, "The effect of intensive diabetes therapy on the development and progression of neuropathy," $A n$ nals of Internal Medicine, vol. 122, pp. 561-568, 1995.

[23] DCCT Research Group, "Effect of intensive diabetes treatment on nerve conduction in the diabetes control and complications trial," Annals of Neurology, vol. 38, no. 6, pp. 869-880, 1995.

[24] P. Reichard, B.-Y. Nilsson, and U. Rosenqvist, "The effect of long-term intensified insulin treatment on the development of microvascular complications of diabetes mellitus," The New England Journal of Medicine, vol. 329, no. 5, pp. 304-309, 1993.

[25] R. Rigler, A. Pramanik, P. Jonasson, et al., "Specific binding of proinsulin C-peptide to human cell membranes," Proceedings of the National Academy of Sciences of the United States of America, vol. 96, no. 23, pp. 13318-13323, 1999.

[26] J. Wahren, K. Ekberg, and H. Jörnvall, "C-peptide is a bioactive peptide,” Diabetologia, vol. 50, no. 3, pp. 503-509, 2007.

[27] C. R. Pierson, W. Zhang, and A. A. F. Sima, "Proinsulin Cpeptide replacement in Type 1 diabetic BB/Wor-rats prevents deficits in nerve fiber regeneration," Journal of Neuropathology \& Experimental Neurology, vol. 62, no. 7, pp. 765-779, 2003.

[28] A. Hansen, B.-L. Johansson, J. Wahren, and H. von Bibra, "Cpeptide exerts beneficial effects on myocardial blood flow and function in patients with Type 1 diabetes," Diabetes, vol. 51, no. 10, pp. 3077-3082, 2002.

[29] B.-L. Johansson, B. Linde, and J. Wahren, "Effects of C-peptide on blood flow, capillary diffusion capacity and glucose utilization in the exercising forearm of Type 1 (insulin-dependent) diabetic patients," Diabetologia, vol. 35, no. 12, pp. 1151-1158, 1992.

[30] B.-L. Johansson, S. Sjöberg, and J. Wahren, "The influence of human C-peptide on renal function and glucose utilization 
in Type 1 (insulin-dependent) diabetic patients," Diabetologia, vol. 35, no. 2, pp. 121-128, 1992.

[31] B.-L. Johansson, H. von Bibra, A. Hansen, and J. Wahren, "Effects of C-peptide on regional myocardial function in patients with Type 1 diabetes," Diabetes, vol. 50, p. A256, 2001.

[32] B.-L. Johansson, K. Borg, E. Fernqvist-Forbes, A. Kernell, T. Odergren, and J. Wahren, "Beneficial effects of C-peptide on incipient nephropathy and neuropathy in patients with Type 1 diabetes mellitus," Diabetic Medicine, vol. 17, no. 3, pp. 181$189,2000$.

[33] S. Sjöberg, R. Gunnarsson, M. Gjötterberg, A. Lefvert, A. Persson, and J. Östman, "Residual insulin production, glycemic control and prevalence of microvascular lesions and polyneuropathy in long-term Type 1 (insulin-dependent) diabetes mellitus," Diabetologia, vol. 30, no. 4, pp. 208-213, 1987.

[34] S. Sjöberg, M. Gjötterberg, L. Berglund, E. Möller, and J. Östman, "Residual C-peptide excretion is associated with a better long-term glycemic control and slower progress of retinopathy in Type I (insulin-dependent) diabetes mellitus," Journal of Diabetic Complications, vol. 5, no. 1, pp. 18-22, 1991.

[35] G. Zerbini, R. Mangili, and L. Luzi, "Higher post-absorptive C-peptide levels in Type 1 diabetic patients without renal complications," Diabetic Medicine, vol. 16, no. 12, pp. 1048-1049, 1999.

[36] M. A. Cotter, K. Ekberg, J. Wahren, and N. E. Cameron, "Effects of proinsulin C-peptide in experimental diabetic neuropathy: vascular actions and modulation by nitric oxide synthase inhibition," Diabetes, vol. 52, no. 7, pp. 1812-1817, 2003.

[37] A. A. F. Sima, W. Zhang, K. Sugimoto, et al., "C-peptide prevents and improves chronic Type I diabetic polyneuropathy in the BB/Wor rat," Diabetologia, vol. 44, no. 7, pp. 889-897, 2001.

[38] M. Stevens, F. Li, W. Zhang, and A. A. F. Sima, "C-peptide prevents impaired endoneurial blood flow but does not effect oxidative stress in Type $1 \mathrm{BB} /$ Wor rats," Journal of the Peripheral Nervous System, vol. 8, p. 196, 2003.

[39] B.-L. Johansson, K. Borg, E. Fernqvist-Forbes, T. Odergren, S. Remahl, and J. Wahren, "C-peptide improves autonomic nerve function in IDDM patients," Diabetologia, vol. 39, no. 6, pp. 687-695, 1996.

[40] Y. Ido, A. Vindigni, K. Chang, et al., "Prevention of vascular and neural dysfunction in diabetic rats by C-peptide," Science, vol. 277, no. 5325, pp. 563-566, 1997.

[41] M. Stevens, J. Dananberg, E. Feldman, et al., “The linked roles of nitric oxide, aldose reductase and, $\left(\mathrm{Na}^{+}, \mathrm{K}^{+}\right)$-ATPase in the slowing of nerve conduction in the streptozotocin diabetic rat," Journal of Clinical Investigation, vol. 94, no. 2, pp. 853859, 1994.

[42] N. Hotta, "New approaches for treatment in diabetes: aldose reductase inhibitors," Biomedecine \& Pharmacotherapy, vol. 49, no. 5, pp. 232-243, 1995.

[43] A. A. F. Sima, V. Bril, V. Nathaniel, et al., "Regeneration and repair of myelinated fibers in sural-nerve biopsy specimens from patients with diabetic neuropathy treated with sorbinil," The New England Journal of Medicine, vol. 319, no. 9, pp. 548-555, 1988.

[44] M. Foppiano and G. Lombardo, "Worldwide pharmacovigilance systems and tolrestat withdrawal," The Lancet, vol. 349, no. 9049, pp. 399-400, 1997.

[45] V. Bril, R. Buchanan, and the AS-3201 Study Group, "Aldose reductase inhibiton by AS-3201 in sural nerve from patients with diabetic sensorimotor polyneuropathy," Diabetes Care, vol. 27, no. 10, pp. 2369-2375, 2004.
[46] V. Bril, R. Buchanan, and the Ranirestat Study Group, "Longterm effects of Ranirestat (AS-3201) on peripheral nerve function in patients with diabetic sensorimotor polyneuropathy," Diabetes Care, vol. 29, no. 1, pp. 68-72, 2006.

[47] A. Vinik, V. Bril, P. Kempler, et al., "Treatment of symptomatic diabetic peripheral neuropathy with the protein kinase $\mathrm{C} \beta$ inhibitor ruboxistaurin mesylate during a 1-year, randomized, placebo-controlled, double-blind clinical trial," Clinical Therapeutics, vol. 27, no. 8, pp. 1164-1180, 2005. 


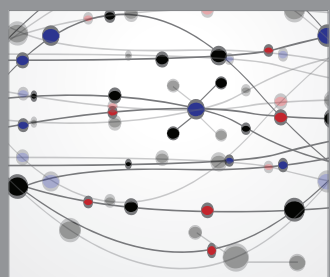

The Scientific World Journal
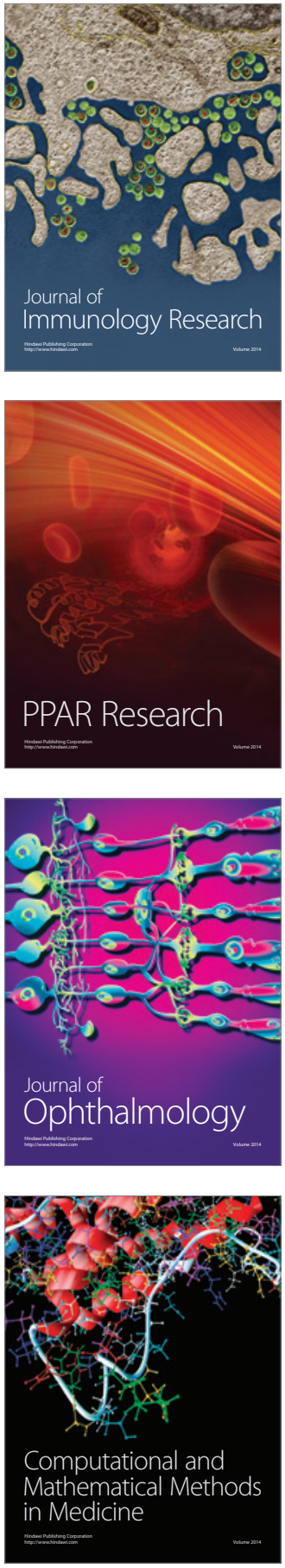



Gastroenterology

Research and Practice
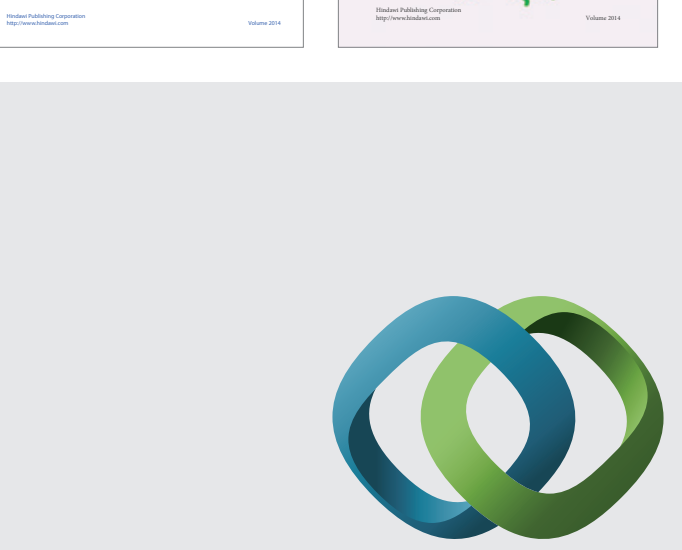

\section{Hindawi}

Submit your manuscripts at

http://www.hindawi.com


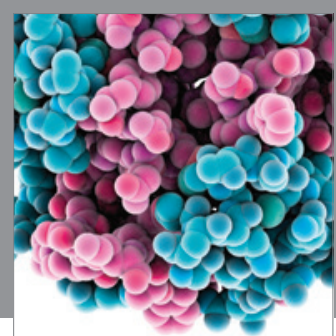

Journal of
Diabetes Research

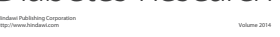

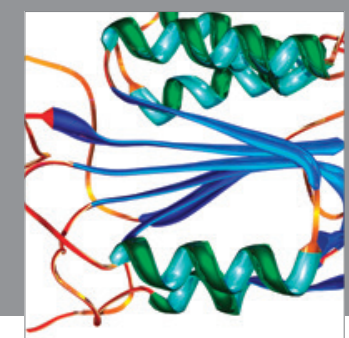

Disease Markers
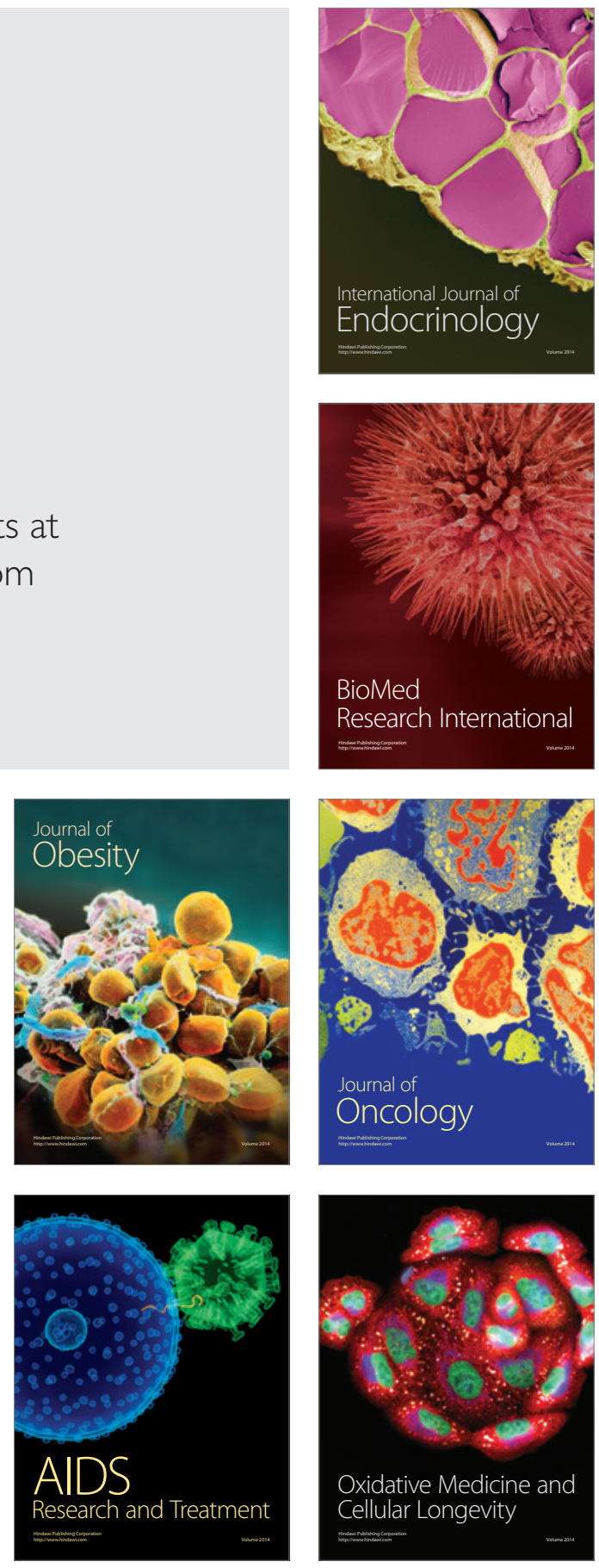